\title{
Kriteria Pemilihan Penggunaan Jasa Bank: Preferensi Nasabah Aktif Bank Syariah dan Bank Konvensional (Dual Banking Customer)
}

\author{
Enny Savitri ${ }^{1}$ \\ ${ }^{1}$ Universitas Pamulang Banten, Fakultas Ekonomi Jurusan Manajemen \\ E-mail: ${ }^{1}$ dosen01700@unpam.ac.id
}

\begin{abstract}
Abstrak
Penelitian ini bertujuan mengidentifikasi kriteria pemilihan pengunaaan jasa bank dari responden nasabah penggunaan jasa bank syariah dan bank konvensional (dual banking customer), memberikan rekomendasi implikasi manajerial khusususnya bagi bank syariah serta memberikan saran yang relevan untuk peningkatan pengguna jasa perbankan syariah. Metode Penelitian yang digunakan adalah analisis deskriptif, analisis faktor dan analisis mean. Analisis deskriptif digunakan untuk menjelaskan demografi responden sedangkan analisis faktor dan analisis mean digunakan untuk mendapatkan aspek yang dominan dinilai oleh nasabah dalam pemilihan penggunaan jasa bank. Hasil penelitian mendapatkan bahwa aspek yang dominan dalam penelitian ini terkait penilaian kriteria pemilihan bank dari nasabah aktif pengguna jasa bank syariah dan bank konvensional (dual banking customer) secara berurutan adalah persepsi reputasi, ketersediaan jaringan dan teknologi, kualitas layanan dan internal bank (karyawan). Implikasi manajerial yang dapat dilakukan oleh bank syariah adalah bank secara individual maupun bersinergi dengan pihak lain dapat melakukan upaya peningkatan intensifitas program literasi keuangan syariah, penyediaan jaringan dan teknologi. Selain itu bank syariah juga harus memberikan pelatihan bagi SDM bank syariah terkait kualitas layanan dan keterampilan karyawan bank. Adapun saran yang diberikan adalah Pemerintah dapat mendorong bank syariah untuk memiliki beberapa fasilitas jaringan dan teknologi secara bersama seperti jaringan ATM, kartu E-Money dan mesin EDC bank syariah bersama.
\end{abstract}

Kata Kunci: kriteria pemilihan bank, nasabah aktif, dual banking customer, analisis faktor

\section{PENDAHULUAN}

Perkembangan bank syariah dmulai dari beroperasinya Bank Muamalat Indonesia dan pada waktu yang relatif bersamaan disahkannya Undang Undang No. 7 Tahun 1992 yang mengatur bahwa perbankan di Indonesia menganut perbankan ganda (dual banking system) dimana perbankan selain beroperasi secara konvensional, dapat juga beroperasi sesuai ketentuan syariah. Kemudian perkembangan regulasi perbankan berikutnya terjadi pada tahun 1998 yang merevisi Undang Undang tahun 1992 dimana bank umum diperbolehkan mendirikan Unit Usaha Syariah. Selanjutnya seiring dengan bertambahnya waktu, perbankan syariah di Indonesia semakin berkembang dan pada tahun 2008 dengan disahkannya Undang Undang No. 21, memberikan kepastian hukum bagi pelaku usaha industri dan 
pengguna jasa perbankan syariah. Dengan keberadaan Undang Undang tersebut semakin menguatkan pertumbuhan

Hingga akhir September 2018 jaringan perbankan syariah di Indonesia terdiri 14 entitas Bank Umum Syariah (BUS), 20 entitas Unit Usaha Syariah (UUS) dan 168 entitas Bank Pembiayaan Rakyat Syariah (BPRS). Adapun jaringan perbankan syariah tersebut mencakup 1.862 unit kantor BUS, 340 unit kantor UUS dan 468 unit kantor BPRS. Jumlah jaringan perbankan syariah masih kalah jumlah, apabila dibandingkan dengan jumlah jaringan perbankan konvensional. Adapun jaringan perbankan konvensional terdiri dari 116 entitas Bank Umum Konvensional (BUK) dan 1.636 entitas Bank Perkreditan Rakyat (BPR). Jaringan perbankan konvensional tersebut mencakup 32.730 unit kantor BUK dan 6.075 unit kantor BPR. Dari data tersebut, menyimpulkan jaringan perbankan syariah, dilihat dari jumlah kantor hanya mencapai 7,02\% dibandingkan dengan jumlah kantor perbankan konvensional.

Secara empiris, perbankan syariah dapat lebih mengoptimalkan peranan intermediasi dalam menyalurkan pembiayaan dibandingkan dengan kredit yang disalurkan oleh perbankan secara keseluruhan. Selama tahun 2014-2017, ratarata FDR (Financing Deposit Ratio) perbankan syariah berada pada $111.23 \%$ sedangkan pada industri perbankan secara keseluruhan hanya mencapai $82.84 \%$. Peranan intermediasi perbankan syariah ini penting karena perbankan syariah dapat berperan sebagai commercial banking dan investment banking yang dapat berkontribusi bagi pertumbuhan ekonomi riil dan meningkatkan produktifitas masyarakat.

Untuk lebih meningkatkan kontrubusi ekonomi tersebut, tentu perbankan syariah

\section{METODE PENELITIAN}

Metode Penelitian ini merupakan jenis perbankan syariah agar dapat beroperasi secara berdampingan dengan bank konvensional.

harus juga meningkatkan market sharenya. Namun hingga akhir September 2018, market share perbankan syariah bila dibandingkan oleh perbankan konvensional yaitu hanya mencapai $5,93 \%$. Pertumbuhan market share suatu bank tentu tidak lepas dari pertumbuhan jumlah Dana Pihak Ketiga (DPK) bank tersebut. Sampai dengan akhir tahun 2017, jumlah DPK perbankan syariah bila dibandingkan oleh perbankan konvensional hanya mencapai $5,67 \%$. Adapun total jumlah rekening nasabah DPK perbankan syariah berjumlah 23,08 juta rekening. Untuk meningkatkan jumlah nasabah pengguna perbankan syariah tentu perbankan syariah harus berkreasi dan berinovasi dalam mengetahui kebutuhan, keinginan, selera dan perilaku nasabah sehingga mereka percaya dan loyal menjadi nasabah pengguna jasa perbankan syariah. .

Penelitian ini merupakan riset dengan objek responden yang berbeda dengan riset terkait kriteria pemilihan bank dari riset-riset sebelumnya. Adapun objek respondennya adalah nasabah aktif pengguna jasa bank syariah dan bank konvensional (dual banking customer). Riset ini bertujuan mengidentifikasi kriteria pemilihan pengunaaan jasa bank dari responden nasabah penggunaan jasa bank syariah dan bank konvensional (dual banking customer), memberikan rekomendasi implikasi manajerial khusususnya bagi bank syariah serta memberikan saran yang relevan untuk peningkatan pengguna jasa perbankan syariah. Riset ini tentu memberikan kontribusi pengetahuan yang semakin melengkapi terkait sejumlah kriteria yang menjadi preferensi nasabah dalam menggunakan jasa perbankan.

penelitian kepustakaan dan survei dimana 
peneliti terlebih dahulu mengkaji kepustakaan yang berkaitan erat dengan permasalahan penelitian. Setelah itu, peneliti membuat kuisioner dan meminta sejumlah responden untuk menjawab kuisioner tersebut. Responden menjawab kuisioner tersebut berdasarkan Analisa Judgement sesuai dengan keyakinan responden tersebut terhadap pertanyaan dan pernyataan yang ada dalam kuisioner. Penelitian ini merupakan jenis riset studi kasus dengan objek penelitian adalah nasabah aktif pengguna jasa bank syariah dan bank konvensional (dual banking customer) berdomisili atau beraktifitas di wilayah Jakarta, Bogor, Depok, Tangerang dan Bekasi.

Dalam penelitian ini, data yang digunakan merupakan data sekunder dan primer. Data sekunder didapat dari literatur buku, jurnal, tesis, disertasi yang menghasilkan sejumlah pertanyaan yang akan diajukan kepada responden dalam daftar isian kuisioner. Jawaban responden atas kuisioner yang diajukan merupakan data primer yang diolah oleh peneliti.

Pemilihan responden dalam penelitian ini dilakukan secara purposive sampling dan non probability sampling ditujukan kepada nasabah aktif pengguna jasa bank syariah dan bank konvensional (dual banking customer) yang berdomisili atau beraktifitas di wilayah Jakarta, Bogor, Depok, Tangerang dan Bekasi. Peneliti ingim mengetahui Preferensi nasabah tersebut. Pengumpulan data yang digunakan dengan melakukan kuisioner mandiri. Kuisioner berisi dua bagian; bagian pertama dirancang

\section{HASIL DAN PEMBAHASAN}

Dalam analisa ini, akan memaparkan terkait seleksi responden, data demografi responden serta aspek dan variabel indikator

\section{Seleksi Responden}

untuk mengumpulkan informasi tentang karakteristik sampel, demografi dan data ekonomi sampel. Pada bagian kedua, responden diminta untuk menjawab sejumlah pertanyaan kualitatif terkait preferensi mereka dalam menggunakan jasa bank. Adapun responden menjawab dengan skala linkert Lima Point dari skal sangat tidak signifikan (skala 1) sampai dengan sangat signifikan (skala 5).

Metode yang digunakan adalah analisa deskriptif, analisis faktor dan analisis mean. Analisis deskriptif berupaya mengungkapkan karakteristik, demografi dan data ekonomi responden dalam suatu bentuk penyajian data yang mudah dimengerti dan diterjemahkan. Analisis faktor berupaya mereduksi sejumlah elemen pertanyaan yang tidak signifikan dan membuat suatu klasifikasi dengan meloading suatu entitas faktor sehingga dapat diketahui elemen dan faktor mana yang memiliki skala prioritas yang tinggi. Analisis faktor digunakan untuk mengidentifikasi 8 kriteria evaluatif (persepsi reputasi, kualitas layanan, daya tarik fisik, rasionalitas nasabah, eksternal bank (pihak lain), internal bank (karyawan), letak lokasi bank dan ketersediaan jaringan dan teknologi. Setelah itu analisis mean digunakan untuk mengungkapkan suatu bentuk penyajian data yang ringkas dengan mendapatkan nilai mean, distribusi frekuensi dan distribusi prosentase serta peringkat prioritas faktor. Setelah itu, peneliti melakukan interpretasi data dan membuat kesimpulan serta rekomendasi berdasarkan temuan penelitian.

penelitian yang digunakan. Berikut masingmasing penjelasannya:

Sebanyak 300 kuisioner dibagikan kepada responden, namun yang dikembalikan 
kepada peneliti sebanyak 251 kuisioner. Dari 251 kuisioner tersebut diseleksi lagi dalam kriteria nasabah aktif (masih memiliki rekening) pada bank konvensional dan bank syariah. Hasil kuisioner yang dapat diproses sebanyak 77 kuisioner atau 30,68 \% dari total responden yang didapat.

\section{Data Demografi Responden}

Informasi demografi yang diperoleh dari responden termasuk gender, umur, agama, status pernikahan, pendidikan terakhir, jenis pekerjaan, jumlah pendapatan sebulan, dan kelompok nasabah bank syariah. Informasi ini diperlukan untuk menentukan bagaimana data demografi dapat dipertimbangkan dalam hal penilaian kriteria pemilihan bank dari nasabah aktif pengguna jasa bank syariah dan bank konvensional (dual banking customer). Berdasarkan data dari 77 responden yang dapat diproses, secara dominan memiliki kriteria: bergender wanita sebanyak 50,6 \%, berusia 25-34 tahun sebanyak 44,1\%, muslim sebanyak 98,7\%, berstatus menikah sebanyak 58,4 \%, telah tamat pendidikan diploma/sarjana sebanyak $61,0 \%$, bekerja sebagai pegawai swasta sebanyak $61,0 \%$, memiliki pendapatan lebih dari Rp 8.000.000,00 per bulan sebanyak 38,9 \% dan merupakan nasabah Bank Syariah Mandiri sebanyak 37,7 \%.

Aspek dan Variabel Indikator Penelitian

Adapun aspek yang diidentifikasi dalam penelitian ini terkait penilaian kriteria pemilihan bank dari nasabah aktif pengguna jasa bank syariah dan bank konvensional (dual banking customer) adalah: (1) persepsi reputasi, (2) kualitas layanan, (3) daya tarik fisik, (4) rasionalitas nasabah, (5) eksternal bank (pihak lain), (6) internal bank (karyawan), (7) letak lokasi bank dan (8) ketersediaan jaringan dan teknologi. Sebanyak 30 variabel indikator diperlukan untuk menjadi rincian bagi kedelapan aspek tersebut. Pada Tabel 1, di bawah ini adalah penjelasannya:

Tabel 1. Aspek dan Variabel Indikator Penelitian

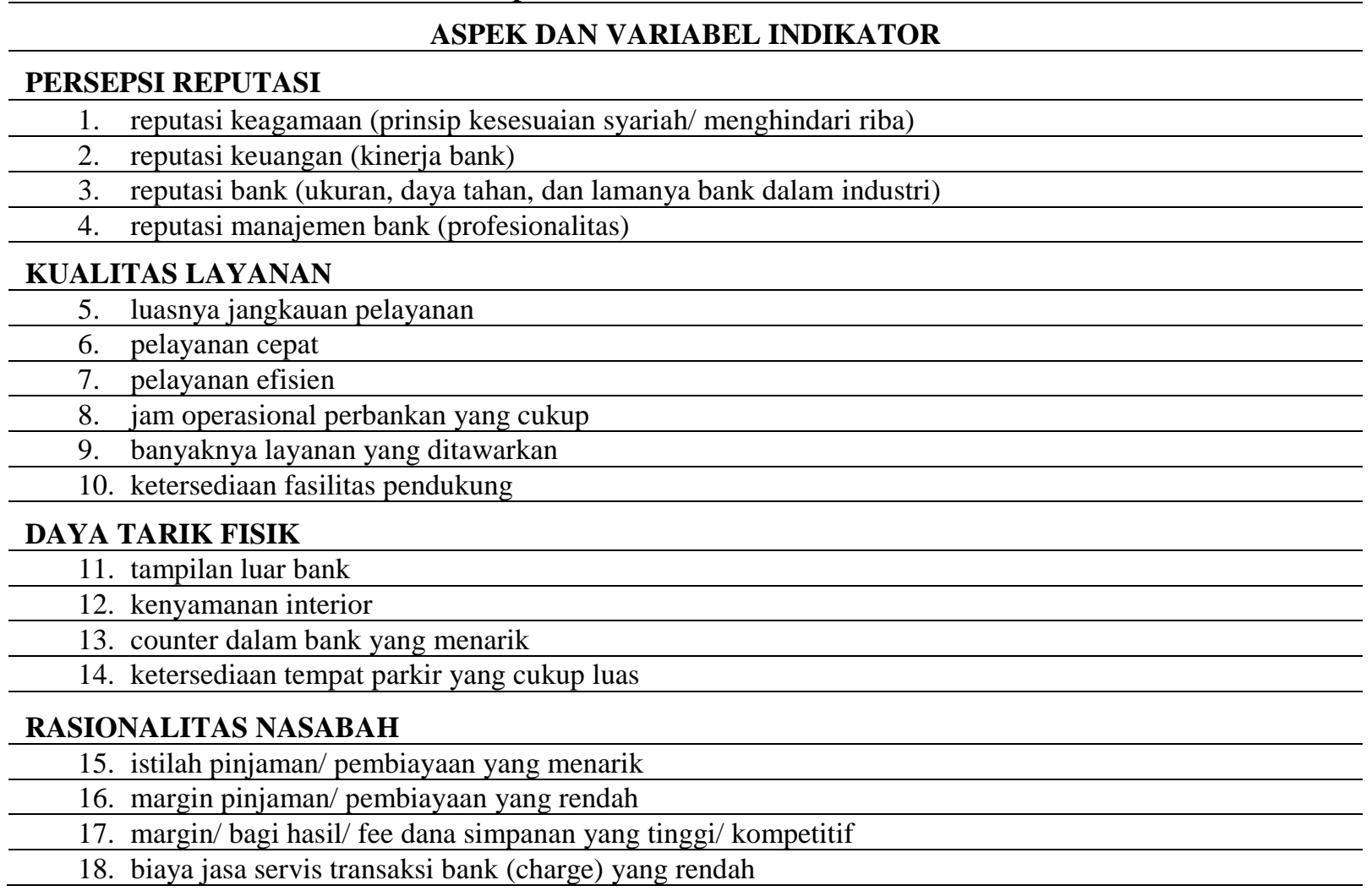


EKSTERNAL BANK (PIHAK LAIN)

19. rekomendasi dari orang/pihak lain

20. organisasi/perusahaan/relasi bisnis menggunakan jasa (rekening) bank yang sama

INTERNAL BANK (KARYAWAN)

21. keramahan layanan personil bank (frontliner)

22. keterampilan karyawan bank yang baik

23. ketersediaan layanan konsultasi keuangan

24. sambutan yang diberikan oleh personil bank

LETAK LOKASI BANK

25. lokasi dekat dengan tempat tinggal

26. lokasi dekat dengan tempat aktifitas/kerja/sekolah

27. lokasi yang strategis dan mudah ditemukan

KETERSEDIAAN JARINGAN DAN TEKNOLOGI

28. ketersediaan jaringan ATM yang cukup

29. ketersediaan sms/internet/online banking

30. ketersediaan keamanan dan kecanggihan teknologi

Sumber: data yang diolah

Dengan menggunakan bantuan SPSS

versi 23, data penelitian yang dapat diproses dari 77 responden dilakukan dengan metode analisis faktor. Berikut adalah tahapannya:

Uji Determinant of Correlation Matrix

Asumsi analisis faktor pertama adalah menguji matriks korelasinya. Matrik korelasi antar variabel dinyatakan saling terkait apabila determinan bernilai mendekati nilai 0. Hasil perhitungan menunjukkan nilai Determinant of Correlation Matrix sebesar 0.00000003929. Nilai ini mendekati 0 (nol), dengan demikian matrik korelasi antara variabel saling terkait.

Uji Kaiser Meyer Olkin Measure of Sampling dan Barlett Test of Spehricity

Asumsi analisis faktor berikutnya adalah: Kaiser Meyer Olkin Measure of Sampling (KMO) adalah indek perbandingan jarak

antara koefisien korelasi dengan koefisien korelasi parsialnya. Jika jumlah kuadrat koefisen korelasi parsial di antara seluruh pasangan variabel bernilai kecil jika dibandingkan dengan jumlah kuadrat koefisien korelasi, maka akan menghasilkan nilai KMO mendekati 1. Nilai KMO dianggap mencukupi jika lebih dari 0,5. Hasil penelitian menunjukkan bahwa nilai Kaiser Meyer Olkin Measure of Sampling sebesar 0,829. Dengan demikian persyaratan KMO memenuhi persyaratan karena memiliki nilai di atas 0,5. Adapun nilai Barlett Test of Spehricity sebesar 2005.973 dengan signifikansi sebesar 0,000. Dengan demikian Bartlett Test of Spehricity memenuhi persyaratan karena signifikansi di bawah 0,05 (5\%). Pada Tabel 2, di bawah ini adalah penjelasannya:

Tabel 2. Nilai KMO dan Bartlett's Test

KMO and Bartlett's Test

\begin{tabular}{lll}
\multicolumn{2}{l}{ Kaiser-Meyer-Olkin Measure of Sampling Adequacy. } & 0.829 \\
\hline Bartlett's Test of Sphericity & Approx. Chi-Square & 2005.973 \\
\hline & Df & 435 \\
\hline & Sig. & 0 \\
\hline
\end{tabular}

Sumber: data yang diolah

\section{Aspek Persepsi Reputasi}

Aspek pertama yang diidentifikasi dalam penelitian ini terkait penilaian kriteria pemilihan bank dari nasabah aktif pengguna jasa bank syariah dan bank konvensional (dual banking customer) adalah persepsi reputasi. Total variabel indikator dalam aspek ini berjumlah 4 item. Variabel yang 
memiliki nilai rata-rata tertinggi yaitu reputasi keagamaan (prinsip kesesuaian syariah/menghindari riba) $(4,42)$ dan reputasi bank (ukuran, daya tahan dan lamanya bank dalam industri) $(4,16)$. Nilai MSA dan loading komunalitas tiap variabel pada faktor ini sudah berada diatas 0,5. Berikut pada Tabel 3, memperlihatkan nilai MSA, loading komunalitas dan rata-rata semua variabel indikator dalam Aspek Persepsi Reputasi.

Tabel 3. Nilai MSA, Loading Komunalitas dan Mean Variabel Indikator Aspek Persepsi Reputasi

\begin{tabular}{|c|c|c|c|}
\hline Aspek Persepsi Reputasi & $\begin{array}{l}\text { Nilai } \\
\text { MSA }\end{array}$ & $\begin{array}{l}\text { Nilai } \\
\text { Loading }\end{array}$ & $\begin{array}{l}\text { Nilai } \\
\text { Mean }\end{array}$ \\
\hline 1. reputasi keagamaan (prinsip kesesuaian syariah/menghindari riba & $.738 \mathrm{a}$ & 0.719 & 4.42 \\
\hline 2. reputasi keuangan (kinerja bank) & $.763 \mathrm{a}$ & 0.743 & 4.10 \\
\hline 3. reputasi bank (ukuran, daya tahan, dan lamanya bank dalam industri) & $.879 \mathrm{a}$ & 0.814 & 4.16 \\
\hline 4. reputasi manajemen bank (profesionalitas) & $.813 \mathrm{a}$ & 0.699 & 4.12 \\
\hline
\end{tabular}

Sumber: data yang diolah

\section{Aspek Kualitas Layanan}

Aspek kedua yang diidentifikasi dalam penelitian ini terkait penilaian kriteria pemilihan bank dari nasabah aktif pengguna jasa bank syariah dan bank konvensional (dual banking customer) adalah kualitas layanan. Total variabel indikator dalam aspek ini berjumlah 6 item. Variabel yang memiliki nilai rata-rata tertinggi yaitu

Tabel 4. Nilai MSA, Loading Komunalitas dan Mean Variabel Indikator Aspek Kualitas Layanan

\begin{tabular}{lllll}
\hline \multicolumn{1}{r}{ Aspek Kualitas Layanan } & Nilai & Nilai & Nilai \\
MSA & Loading & Mean \\
\hline 1. & luasnya jangkauan pelayanan & $.929 \mathrm{a}$ & 0.737 & $\mathbf{4 . 1 3}$ \\
\hline 2. & pelayanan cepat & $.862 \mathrm{a}$ & 0.763 & $\mathbf{4 . 1 3}$ \\
\hline 3. & pelayanan efisien & $.787 \mathrm{a}$ & 0.884 & $\mathbf{4 . 1 4}$ \\
\hline 4. & jam operasional perbankan yang cukup & $.902 \mathrm{a}$ & 0.803 & 3.96 \\
\hline 5. & banyaknya layanan yang ditawarkan & $.805 \mathrm{a}$ & 0.742 & 3.99 \\
\hline 6. & ketersediaan fasilitas pendukung & $.809 \mathrm{a}$ & 0.670 & 4.12 \\
\hline
\end{tabular}

Sumber: data yang diolah

\section{Aspek Daya Tarik Fisik}

Aspek ketiga yang diidentifikasi dalam penelitian ini terkait penilaian kriteria pemilihan bank dari nasabah aktif pengguna jasa bank syariah dan bank konvensional (dual banking customer) adalah daya tarik fisik. Total variabel indikator dalam aspek ini berjumlah 4 item. Variabel yang memiliki nilai rata-rata tertinggi yaitu

Tabel 5. Nilai MSA, Loading Komunalitas dan Mean Variabel Indikator Aspek Daya Tarik Fisik pelayanan efisien $(4,14)$, pelayanan cepat $(4,13)$ dan luasnya jangkauan pelayanan $(4,13)$. Nilai MSA dan loading komunalitas tiap variabel pada faktor ini sudah berada diatas 0,5. Berikut pada Tabel 4, memperlihatkan nilai MSA, loading komunalitas dan rata-rata semua variabel indikator dalam Aspek Kualitas Layanan. kenyamanan interior $(3,58)$ dan counter dalam bank yang menarik $(3,53)$. Nilai MSA dan loading komunalitas tiap variabel pada faktor ini sudah berada diatas 0,5. Berikut pada Tabel 5, memperlihatkan nilai MSA, loading komunalitas dan rata-rata semua variabel indikator dalam Aspek Daya Tarik Fisik.

Aspek Daya Tarik Fisik

Nilai Nilai Nilai

MSA Loading Mean




\begin{tabular}{rlrrr}
\hline 1. & tampilan luar bank & $.849 \mathrm{a}$ & 0.748 & 3.45 \\
\hline 2. & kenyamanan interior & $.859 \mathrm{a}$ & 0.812 & $\mathbf{3 . 5 8}$ \\
\hline 3. & counter dalam bank yang menarik & $.815 \mathrm{a}$ & 0.745 & $\mathbf{3 . 5 3}$ \\
\hline 4. & ketersediaan tempat parker yang luas & $.878 \mathrm{a}$ & 0.757 & 3.43 \\
\hline
\end{tabular}

Sumber: data yang diolah

\section{Aspek Rasionalitas Nasabah}

Aspek keempat yang diidentifikasi dalam penelitian ini terkait penilaian kriteria pemilihan bank dari nasabah aktif pengguna jasa bank syariah dan bank konvensional (dual banking customer) adalah rasionalitas nasabah. Total variabel indikator dalam aspek ini berjumlah 4 item. Variabel yang memiliki nilai rata-rata tertinggi yaitu biaya jasa servis transaksi bank (charge) yang

Tabel 6. Nilai MSA, Loading Komunalitas dan Mean Variabel Indikator Aspek Rasionalitas Nasabah

\begin{tabular}{rlcll}
\hline & Aspek Rasionalitas Nasabah & Nilai & Nilai & Nilai \\
LSA & Loading & Mean \\
\hline 1. & istilah pinjaman/ pembiayaan yang menarik & $.849 \mathrm{a}$ & 0.694 & 3.57 \\
\hline 2. & margin pinjaman/ pembiayaan yang rendah & $.743 \mathrm{a}$ & 0.751 & 3.60 \\
\hline 3. & margin/ bagi hasil/ fee dana simpanan yang tinggi/ kompetitif & $.657 \mathrm{a}$ & 0.795 & $\mathbf{3 . 7 4}$ \\
\hline 4. & biaya jasa servis transaksi bank (charge) yang rendah & $.765 \mathrm{a}$ & 0.804 & $\mathbf{4 . 0 0}$ \\
\hline
\end{tabular}

Sumber: data yang diolah

Aspek Eksternal Bank (Pihak Lain)

Aspek kelima yang diidentifikasi dalam penelitian ini terkait penilaian kriteria pemilihan bank dari nasabah aktif pengguna jasa bank syariah dan bank konvensional (dual banking customer) adalah eksternal bank (pihak lain). Total variabel indikator dalam aspek ini berjumlah 2 item. Variabel yang memiliki nilai rata-rata tertinggi yaitu rendah $(4,00)$ dan margin/ bagi hasil/ fee danan simpanan yang tinggi/ kompetitif $(3,74)$. Nilai MSA dan loading komunalitas tiap variabel pada faktor ini sudah berada diatas 0,5. Berikut pada Tabel 6, memperlihatkan nilai MSA, loading komunalitas dan rata-rata semua variabel indikator dalam Aspek Rasionalitas Nasabah.

Tabel 7. Nilai MSA, Loading Komunalitas dan Mean Variabel Indikator Aspek Eksternal Bank (Pihak Lain)

\begin{tabular}{|c|c|c|c|}
\hline Aspek Eksternal Bank (Pihak Lain) & $\begin{array}{l}\text { Nilai } \\
\text { MSA }\end{array}$ & $\begin{array}{l}\text { Nilai } \\
\text { Loading }\end{array}$ & $\begin{array}{l}\text { Nilai } \\
\text { Mean }\end{array}$ \\
\hline 1. rekomendasi dari orang/ pihak lain & $.834 \mathrm{a}$ & 0.609 & 3.55 \\
\hline $\begin{array}{l}\text { 2. organisasi/ perusahaan/ relasi bisnis menggunakan jasa (rekening) } \\
\text { bank yang sama }\end{array}$ & $.815 \mathrm{a}$ & 0.665 & 3.74 \\
\hline
\end{tabular}

Sumber: data yang diolah

\section{Aspek Internal Bank (Karyawan)}

Aspek keenam yang diidentifikasi dalam penelitian ini terkait penilaian kriteria pemilihan bank dari nasabah aktif pengguna jasa bank syariah dan bank konvensional organisasi/ perusahaan/ relasi bisnis menggunakan jasa (rekening) bank yang sama (3,74). Nilai MSA dan loading komunalitas tiap variabel pada faktor ini sudah berada diatas 0,5 . Berikut pada Tabel 7, memperlihatkan nilai MSA, loading komunalitas dan rata-rata semua variabel indikator dalam Aspek Eksternal Bank (Pihak Lain). (dual banking customer) adalah internal bank (karyawan). Total variabel indikator dalam aspek ini berjumlah 4 item. Variabel yang memiliki nilai rata-rata tertinggi yaitu keramahan layanan personil bank 
(frontliner) (4,19). Nilai MSA dan loading komunalitas tiap variabel pada faktor ini sudah berada diatas 0,5 . Berikut pada Tabel 8, memperlihatkan nilai MSA, loading komunalitas dan rata-rata semua variabel indikator dalam Aspek Internal Bank (Karyawan).

Tabel 8. Nilai MSA, Loading Komunalitas dan Mean Variabel Indikator

Aspek Internal Bank (Karyawan)

\begin{tabular}{|c|c|c|c|}
\hline Aspek Internal Bank (Karyawan) & $\begin{array}{l}\text { Nilai } \\
\text { MSA }\end{array}$ & $\begin{array}{l}\text { Nilai } \\
\text { Loading }\end{array}$ & $\begin{array}{l}\text { Nilai } \\
\text { Mean }\end{array}$ \\
\hline 1. keramahan layanan personil bank (frontliner) & $.881 \mathrm{a}$ & 0.771 & 4.19 \\
\hline 2. keterampilan karyawan bank yang baik & $.907 \mathrm{a}$ & 0.696 & 3.99 \\
\hline 3. ketersediaan layanan konsultasi keuangan & $.878 \mathrm{a}$ & 0.721 & 3.81 \\
\hline 4. sambutan yang diberikan oleh personil bank & $.802 \mathrm{a}$ & 0.722 & 3.99 \\
\hline
\end{tabular}

Sumber: data yang diolah

\section{Aspek Letak Lokasi Bank}

Aspek ketujuh yang diidentifikasi dalam penelitian ini terkait penilaian kriteria pemilihan bank dari nasabah aktif pengguna jasa bank syariah dan bank konvensional (dual banking customer) adalah letak lokasi bank. Total variabel indikator dalam aspek ini berjumlah 3 item. Variabel yang memiliki nilai rata-rata tertinggi yaitu lokasi dekat dengan tempat aktifitas/ kerja/ sekolah (4,04). Nilai MSA dan loading komunalitas tiap variabel pada faktor ini sudah berada diatas 0,5. Berikut pada Tabel 9, memperlihatkan nilai MSA, loading komunalitas dan rata-rata semua variabel indikator dalam Aspek Letak Lokasi Bank.

Tabel 9. Nilai MSA, Loading Komunalitas dan Mean Variabel Indikator

Aspek Letak Lokasi Bank

\begin{tabular}{|c|c|c|c|}
\hline Aspek Letak Lokasi Bank & $\begin{array}{l}\text { Nilai } \\
\text { MSA }\end{array}$ & $\begin{array}{l}\text { Nilai } \\
\text { Loading }\end{array}$ & $\begin{array}{l}\text { Nilai } \\
\text { Mean }\end{array}$ \\
\hline 1. lokasi dekat dengan tempat tinggal & $.779 \mathrm{a}$ & 0.705 & 3.88 \\
\hline 2. lokasi dekat dengan tempat aktifitas/ kerja/ sekolah & $.822 \mathrm{a}$ & 0.656 & 4.04 \\
\hline 3. lokasi yang strategis dan mudah ditemukan & $.841 \mathrm{a}$ & 0.684 & 4.00 \\
\hline
\end{tabular}

Sumber: data yang diolah

\section{Aspek Ketersediaan Jaringan dan Teknologi}

Aspek kedelapan yang diidentifikasi dalam penelitian ini terkait penilaian kriteria pemilihan bank dari nasabah aktif pengguna jasa bank syariah dan bank konvensional (dual banking customer) adalah ketersediaan jaringan dan teknologi. Total variabel indikator dalam aspek ini berjumlah 3 item.
Variabel yang memiliki nilai rata-rata tertinggi yaitu ketersediaan sms/ internet/ online banking $(4,25)$. Nilai MSA dan loading komunalitas tiap variabel pada faktor ini sudah berada diatas 0,5. Berikut pada Tabel 10, memperlihatkan nilai MSA, loading komunalitas dan rata-rata semua variabel indikator dalam Aspek Jaringan dan Teknologi.

Tabel 10. Nilai MSA, Loading Komunalitas dan Mean Variabel Indikator Aspek Ketersediaan Jaringan dan Teknologi

\begin{tabular}{lllll}
\hline & Aspek Ketersediaan Jaringan dan Teknologi & Nilai & Nilai & Nilai \\
Loading & Mean \\
\hline 1. & ketersediaan jaringan ATM yang cukup & $.880 \mathrm{a}$ & 0.780 & 4.10 \\
\hline 2. & ketersediaan sms/ internet/ online banking & $.765 \mathrm{a}$ & 0.744 & $\mathbf{4 . 2 5}$ \\
\hline 3. & ketersediaan keamanan dan kecanggihan teknologi & $.811 \mathrm{a}$ & 0.757 & 4.23 \\
\hline
\end{tabular}

Sumber: data yang diolah 
Berdasarkan data-data diatas, dapat disimpulkan bahwa semua variabel secara simultan telah memenuhi syarat validitas (nilai KMO = 0,829), semua variabel secara masing-masing telah memenuhi syarat reabilitas (nilai MSA > 0,5) dan semua variabel secara masing-masing telah

Untuk memberikan pemahaman lebih lanjut terkait masalah penelitian, kedelapan aspek tersebut dicari peringkat faktornya dengan menghitung nilai komposit. Nilai komposit dihitung dengan membagi rata-rata total dari setiap item yang dimuat dalam aspek dengan jumlah item yang dimuat dalam aspek masing-masing. Aspek yang dominan dalam penelitian ini terkait memenuhi syarat komunalitas (nilai loading $>0,5)$. Dengan demikian bahwa 30 variabel yang menjadi indikator dari 8 aspek, mampu menerangkan kriteria pemilihan bank menurut responden dari nasabah aktif pengguna jasa bank syariah dan bank konvensional.

penilaian kriteria pemilihan bank dari nasabah aktif pengguna jasa bank syariah dan bank konvensional (dual banking customer) secara berurutan adalah persepsi reputasi $(4,20)$, ketersediaan jaringan dan teknologi $(4,19)$, kualitas layanan $(4,08)$ dan internal bank (karyawan) $(3,99)$. Untuk lebih jelasnya dapat dilihat pada Tabel 11 dibawah ini:

Tabel 11. Prioritas Aspek

\begin{tabular}{lcccc}
\hline \multicolumn{1}{c}{ Aspek } & Total Mean & Jumlah Variabel & Nilai Komposit & Peringkat \\
\hline Persepsi Reputasi & 16.79 & 4 & 4.20 & 1 \\
\hline Ketersediaan Jaringan dan Teknologi & 12.58 & 3 & 4.19 & 2 \\
\hline Kualitas Layanan & 24.47 & 6 & 4.08 & 3 \\
\hline Internal Bank (Karyawan) & 15.97 & 4 & 3.99 & 4 \\
\hline Letak Lokasi Bank & 11.92 & 3 & 3.97 & 5 \\
\hline Rasionalitas Nasabah & 14.91 & 4 & 3.73 & 6 \\
\hline Eksternal Bank (Pihak Lain) & 7.29 & 2 & 3.64 & 7 \\
\hline Daya Tarik Fisik & 14.00 & 4 & 3.50 & 8 \\
\hline
\end{tabular}

Sumber: data yang diolah

Berdasarkan hasil analisis, implikasi manajerial yang dapat dirumuskan:

a). Meningkatkan intensifitas program literasi keuangan syariah

Nasabah aktif pengguna jasa bank syariah yang sekaligus juga merupakan nasabah aktif pengguna jasa bank konvensional, dalam kriteria pemilihan bank dominan mempertimbangkan aspek persepsi reputasi terutama reputasi keagamaan (prinsip kesesuaian syariah/ menghindari riba) lalu berikutnya reputasi bank (ukuran, daya tahan dan lamanya bank dalam industri). Dengan demikian perlu ada peningkatan intensifitas program literasi keuangan syariah khususnya literasi perbankan syariah agar nasabah yang hanya sebagai pengguna jasa bank konvensional juga dapat menjadi pengguna jasa bank syariah. b). Meningkatkan ketersediaan jaringan dan teknologi baik secara internal maupun bersinergi dengan bank syariah serta IKNB (Institusi Keuangan Non Bank) syariah lainnya

Kriteria lain bagi dual banking customer dalam pemilihan bank berikutnya, juga mempertimbangkan aspek ketersediaan jaringan dan teknologi terutama ketersediaan sms/ internet/ online banking. Kriteria berikutnya adalah aspek kualitas layanan terutama pelayanan efisien, pelayanan cepat dan luasnya jangkauan pelayanan. Dengan demikian perlu ada upaya secara individual bank maupun sinergisitas dengan institusi lainnya dalam penyediaan jaringan dan teknologi dengan ketersediaan layanan sms/ internet/ online banking serta teknologi yang dapat meningkatkan efisiensi, kecepatan dan luasnya jangkauan pelayanan bank syariah 
seperti membuat jaringan ATM, kartu EMoney dan mesin EDC bank syariah bersama.

c). Meningkatkan pelatihan bagi SDM bank syariah terkait kualitas layanan dan keterampilan karyawan bank

Nasabah aktif pengguna jasa bank syariah dan bank konvensional (dual banking KESIMPULAN DAN SARAN

Berdasarkan hasil penelitian, didapatkan kesimpulan bahwa:

1. Terdapat 8 aspek yang dinilai terkait penilaian kriteria pemilihan bank dari nasabah aktif pengguna jasa bank syariah dan bank konvensional (dual banking customer) yaitu; (a) persepsi reputasi, (b) kualitas layanan, (c) daya tarik fisik, (d) rasionalitas nasabah, (e) eksternal bank (pihak lain), (f) internal bank (karyawan), (g) letak lokasi bank dan (h) ketersediaan jaringan dan teknologi. Sebanyak 30 variabel indikator diperlukan untuk menjadi rincian bagi kedelapan aspek tersebut.

2. Aspek yang dominan dalam penelitian ini terkait penilaian kriteria pemilihan bank dari nasabah aktif pengguna jasa bank syariah dan bank konvensional (dual banking customer) secara berurutan adalah persepsi reputasi $(4,20)$, ketersediaan jaringan dan teknologi $(4,19)$, kualitas layanan $(4,08)$ dan internal bank (karyawan) $(3,99)$.

Riset ini memberikan kontribusi pengetahuan yang semakin melengkapi terkait sejumlah kriteria yang menjadi preferensi nasabah dalam menggunakan jasa perbankan. Secara umum saran yang dapat diberikan adalah:

1. Bank Syariah secara individual maupun bersinergi dengan pihak lain dapat melakukan upaya peningkatan intensifitas program literasi keuangan syariah, penyediaan jaringan dan teknologi. Selain itu bank syariah juga harus memberikan pelatihan bagi SDM customer) juga mempertimbangkan kualitas SDM bank dalam memberikan layanan yang bersahabat dan keterampilan karyawan bank tersebut. Dengan demikian perlu ada upaya peningkatan kuantitas pelatihan SDM bank yang berkualitas dalam pemberian layanan dan kompetensi personil.

bank syariah terkait kualitas layanan dan keterampilan karyawan bank.

2. Untuk meningkatkan jumlah nasabah bank syariah, Pemerintah dapat mendorong bank syariah untuk memiliki beberapa fasilitas jaringan dan teknologi secara bersama seperti jaringan ATM, kartu E-Money dan mesin EDC bank syariah bersama.

\section{DAFTAR PUSTAKA}

Abduh, M. (2011). Preferensi konsumen bank syariah. Jurnal Iqthisodia Republika. Kamis, 24 Februari 2011.

Abdullah, A.A. Sidek, R. Adnan, A.A. (2012). Perception of non-muslims customers towards islamic banks in malaysia. International Journal of Business and Social Science. Vol 3 No. 11, 2012.

Abhimantra, A. Maulina, A.R. Agustianingsih, E. (2013). Analisis faktorfaktor yang mempengaruhi nasabah (mahasiswa) dalam memilih menabung pada bank syariah. Prosiding PESAT (Psikologi, Ekonomi, Sastra, Arsitektur \& Teknik Sipil), 8-9 Oktober 2013.

Adawiyah, W.R. (2010). Pertimbangan, pengetahuan, dan sikap konsumen individu terhadap bank syariah. Jurnal Ekonomi Pembangunan. Vol. 11 (2): 191-201.

Ahmad, K. Rustam, G.A. Dent, M.M. (2011). Brand preference in Islamic banking. Journal of Islamic Marketing. Vol. 2 (1): 74-82.

Ahmad, W.M.W. Rahman, A.Ab. Seman, A.C. Ali, N.A. (2008). Religiosity and 
banking selection criteria among malays in lembah klang. Shariah Journal. Vol. 16 (2): 99-130.

Dusuki, A.W.D. Abdullah, N.I. (2007). Why do malaysian customers patronize Islamic banks?. International Journal of Bank Marketing. Vol. 25 (3): 142-160.

Kamdari, N.A.Md. Sulaiman, Z. Yusoff, R. (2008). Customer perception: in using Islamic product and services between BIMB and conventional banks (maybank) in segamat, johor. conference paper. 2008.

Mansour, W. Abdelhamid, M.B. Masood, O. Niazi, G.S.K. (2010). Islamic banking and customers' preferences: the case of the UK. Qualitative Research in Financial Markets. Vol 2. (3): 185-199.

Marimuthu, M. Jing, C.W. Gie, L.P. Mun, L.P. Ping, T.Y. (2010). Islamic banking: selection criteria and implications. Global Journal of Human Social Science. Vol. 10 No. 4, 2010

[OJK] Otoritas Jasa Keuangan. (2018). Laporan publikasi statistik perbankan syariah. Jakarta.
Pinar, M. Girard, T. Eser, Z. (2012). Consumer-based brand equity in banking industry: a comparison of local and global banks in Turkey. International Journal of Bank Marketing. Vol. 30 (5): 359-375.

[RI]. Republik Indonesia. (2008). UndangUndang No. 21 Tahun 2008 Tentang Perbankan Syariah.

Rivai, Veithzal dkk. (2007), Bank \& Financial Institution Management, Rajawali Press, Jakarta

Sari, Y. Sumarwan, U. Hosen, M.N. (2016). Analisis faktor-faktor preferensi Etnis Tionghoa Terhadap Bank Syariah di Indonesia. Jurnal Al-Muzara'ah. Vol. 3 No. 1, 2016.

Sudarsono H. (2008). Bank dan Lembaga Keuangan Syariah. Deskripsi dan Ilustrasi. Yogyakarta(ID): EKONISIA

Tamimi, H.A.H. Kalli, A.A.B. (2009). Financial literacy and investment decisions of UAE. The Journal of Risk Finance. Vol. 10 No. 5, 2009. 